\title{
Visual Receptive Field Properties of Neurons in the Superficial Superior Colliculus of the Mouse
}

\author{
Lupeng Wang, ${ }^{1,2 \star}$ Rashmi Sarnaik, ${ }^{1,2 \star}$ Krsna Rangarajan, ${ }^{1}$ Xiaorong Liu, ${ }^{1}$ and Jianhua Cang ${ }^{1}$ \\ ${ }^{1}$ Department of Neurobiology and Physiology, and ${ }^{2}$ Interdepartmental Neuroscience Program, Northwestern University, Evanston, Illinois 60208
}

The mouse is a promising model in the study of visual system function and development because of available genetic tools. However, a quantitative analysis of visual receptive field properties had not been performed in the mouse superior colliculus (SC) despite its importance in mouse vision and its usefulness in developmental studies. We have made single-unit extracellular recordings from superficial layers of the SC in urethane-anesthetized C57BL/6 mice. We first map receptive fields with flashing spot stimuli and show that most SC neurons have spatially overlapped ON and OFF subfields. With drifting sinusoidal gratings, we then determine the tuning properties of individual SC neurons, including selectivity for stimulus direction and orientation, spatial frequency tuning, temporal frequency tuning, response linearity, and size preference. A wide range of receptive field sizes and selectivity are observed across the population and in various subtypes of SC neurons identified morphologically. In particular, orientation-selective responses are discovered in the mouse SC, and they are not affected by cortical lesion or long-term visual deprivation. However, ON/OFF characteristics and spatial frequency tuning of SC neurons are influenced by cortical inputs and require visual experience during development. Together, our results provide essential information for future investigations on the functional development of the superior colliculus.

\section{Introduction}

Mice have gradually become a model system in vision research. This is mainly attributable to two reasons. First, advances in mouse genetics have made it possible to identify subtypes of neurons within a given brain structure, to trace synaptic connectivity, and to manipulate gene expression and neuronal activity in a spatially and temporally controlled manner (Callaway, 2005; Zhang et al., 2007; Luo et al., 2008). These genetic tools provide great promise to the study of visual system function and development. Indeed, several subtypes of retinal ganglion cells (RGCs) have been identified in mice and their response properties and projection patterns are being revealed (Huberman et al., 2008, 2009; Kim et al., 2008). Second, recent behavioral and physiological studies have demonstrated that the mouse visual system has better capabilities than previously thought and it possesses most of the functional features seen in higher mammals (Prusky and Douglas, 2004; Prusky et al., 2004; Niell and Stryker, 2008; Umino et al., 2008). The receptive fields in mouse dorsal lateral geniculate nucleus (dLGN) and primary visual cortex (V1) have been recharacterized recently using modern visual stimuli and quantitative analyses (Grubb and Thompson, 2003; Niell and Stryker, 2008). Surprisingly, the

Received June 25, 2010; revised Sept. 7, 2010; accepted 0ct. 12, 2010.

This work was supported by National Institutes of Health Grants EY018621 (J.C.) and EY019034 (X.L.), a Sloan Research Fellowship, a Klingenstein Fellowship Award in Neurosciences, and a Brain Research Foundation Seed Grant (J.C.). We thank Bor-Shuen Wang and Martha Vitaterna for their help with dark rearing, and Francois Grimbert, David Feldheim, Jason Triplett, and Dan Butts for their comments.

*L.W. and R.S. contributed equally to this work.

Correspondence should be addressed to Jianhua Cang at the above address. E-mail: cang@northwestern.edu. DOI:10.1523/JNEUROSCI.3305-10.2010

Copyright $\odot 2010$ the authors $\quad 0270-6474 / 10 / 3016573-12 \$ 15.00 / 0$ superior colliculus (SC) has not been restudied with a similar approach, despite its importance in mouse vision and in the studies of topographic map formation.

The SC is the most prominent retinal target in the mouse. It is estimated that at least $70 \%$ of mouse RGCs project to the superficial layers of the SC (Hofbauer and Dräger, 1985), where their axons are organized in a retinotopic manner (McLaughlin and O'Leary, 2005). In rodents, the SC also receives cortical projections that are aligned with the retinocollicular map (Rhoades and Chalupa, 1978). The use of mouse genetics has greatly advanced our understanding of how retinocollicular maps are established during development (Clandinin and Feldheim, 2009) and matched with corticocollicular projections (Triplett et al., 2009). The transgenic mice generated in these studies thus provide great opportunities to investigate how retinal and cortical projections each contribute to the development of SC functions (Chandrasekaran et al., 2007, 2009; L. Wang et al., 2009). Importantly, such investigations would require the knowledge of receptive field properties in the wild-type SC. Furthermore, given that the SC is heavily innervated by both the retina and cortex and that visual deprivation in rodents affects the two structures differently (Fagiolini et al., 2003; Elstrott et al., 2008), it is of great interest to study whether visual experience is required for the normal development of collicular receptive fields.

The purpose of the current study is therefore threefold: (1) to quantitatively describe visual receptive field properties in the SC of wild-type mice, (2) to reveal cortical influence on $S C$ receptive fields, and (3) to determine the requirement of visual experience in SC receptive field development. The obtained results will thus provide a foundation for future studies using genetic methods to 
investigate the synaptic basis and developmental mechanisms of SC receptive fields.

\section{Materials and Methods}

Animals. C57BL/6 mice of both genders and $>6$ weeks of age were used in this study. They were housed either under $12 \mathrm{~h}$ light/dark cycle, or in constant darkness from birth to the day of recording for $\sim 2$ months. All animals were used in accordance with protocols approved by Northwestern University Institutional Animal Care and Use Committee.

In vivo electrophysiology. Following our published protocols (L. Wang et al., 2009; B. S. Wang et al., 2010), mice were anesthetized with urethane $(1.2-1.3 \mathrm{~g} / \mathrm{kg}$ in $10 \%$ saline solution, i.p.) and supplemented with the sedative chlorprothixene $(10 \mathrm{mg} / \mathrm{kg}$ in $4 \mathrm{mg} / \mathrm{ml}$ water solution, i.m.). Atropine $(0.3 \mathrm{mg} / \mathrm{kg})$ and dexamethasone $(2.0 \mathrm{mg} / \mathrm{kg})$ were injected subcutaneously to minimize mucus secretion and edema, respectively. Additional urethane (0.2$0.3 \mathrm{~g} / \mathrm{kg}$ ) was administered as needed. A tracheotomy was performed and electrocardiograph leads were attached across the skin to monitor the heart rate continuously throughout the experiment. The animal's temperature was monitored with a rectal thermo probe and maintained at $37^{\circ} \mathrm{C}$ through a feedback heater control module (Frederick Haer Company). Silicone oil was applied on the eyes to prevent from drying. A craniotomy $\left(4-8 \mathrm{~mm}^{2}\right.$ for SC recording and $\sim 2 \mathrm{~mm}^{2}$ for $\mathrm{V} 1$ ) was then performed on the left hemisphere to expose the brain for recording with 5-10 $\mathrm{M} \Omega$ tungsten microelectrodes (FHC). Electrical signals, both spikes (filtered between 0.5 and $7 \mathrm{kHz}$ and sampled at $25 \mathrm{kHz}$ ) and field potentials (filtered between 10 and $300 \mathrm{~Hz}$ and sampled at $800 \mathrm{~Hz}$ ), were acquired using a System 3 workstation (Tucker-Davis Technologies), and the spike waveforms were further sorted off-line into single units using OpenSorter (Tucker-Davis Technologies).

For SC recordings with intact cortex, the electrodes were inserted vertically into the overlaying cortex at a distance of $0.7-1.5 \mathrm{~mm}$ lateral of the midline suture and $0.2-0.8 \mathrm{~mm}$ anterior to the lambda suture. The identification of SC surface (located 1-1.5 mm below the cortical surface) followed the procedure in our previous study (L. Wang et al., 2009). Only neurons within $300 \mu \mathrm{m}$ below the SC surface were included in our analysis, corresponding to the superficial retinal recipient layers of the SC. V1 recordings were performed at $2.8-3.3 \mathrm{~mm}$ lateral from the midline and $0.5-1.0 \mathrm{~mm}$ anterior from the lambda suture (Cang et al., 2005). Penetrations were made perpendicular to the pial surface and up to a depth of $700 \mu \mathrm{m}$, thus including cells across all layers of the visual cortex. To record from the SC in the absence of cortical inputs, $\sim 4 \times 4 \mathrm{~mm}^{2}$ overlaying tissues (from midline and lambda suture) were removed by aspiration to expose the SC, before inserting tungsten electrodes. The animals were killed at the end of recordings by an overdose of euthanasia solution (150 mg/kg pentobarbital, in Euthasol; Virbac). The lesioned brains were then perfused and sectioned to confirm the extent of cortical lesion.

Visual stimuli and data analysis. Visual stimuli were generated with customized Matlab programs (Niell and Stryker, 2008) using the Psychophysics Toolbox extensions (Brainard, 1997; Pelli, 1997). The stimuli were displayed on a flat panel cathode ray tube video monitor $(40 \times 30$ $\mathrm{cm}, 60 \mathrm{~Hz}$ refresh rate, $\sim 35 \mathrm{~cd} / \mathrm{m}^{2}$ mean luminance) placed $25 \mathrm{~cm}$ from the animal, and delivered to the eye contralateral to the recorded hemisphere while the ipsilateral eye was occluded. With the animal's eyes $\sim 5$ $\mathrm{cm}$ above the lower edge of the monitor, the monitor covered $\sim 0-80^{\circ}$
B

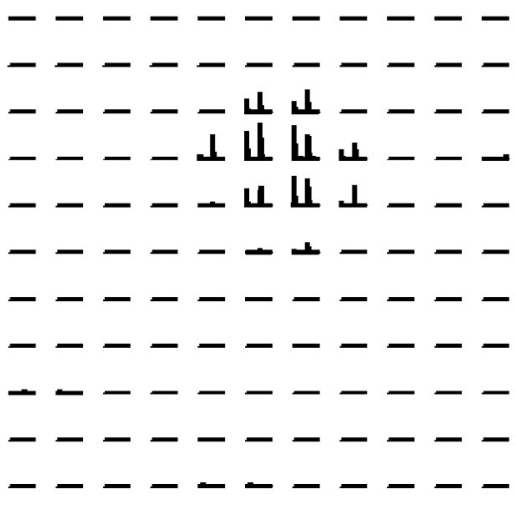

$\mathrm{E}$

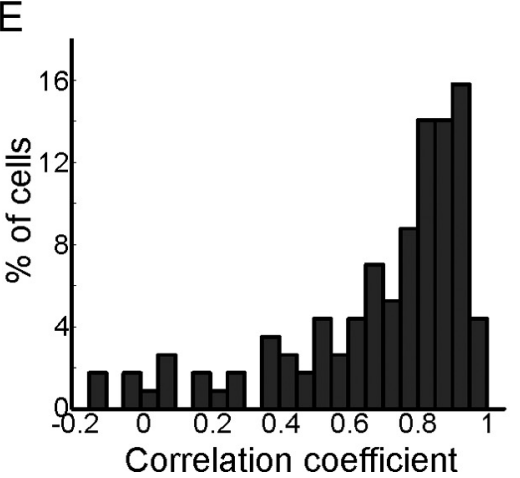

C

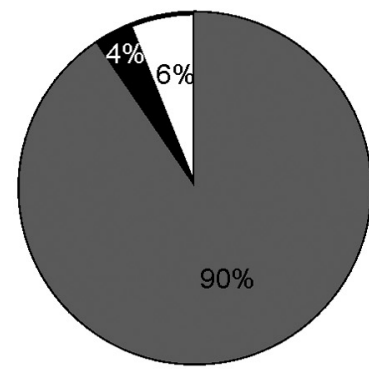

Figure 1. Responses of SC neurons to flashing spots. A, Spike rasters (middle panel) and peristimulus time histograms (PSTHs) ( $.11 \pm 0.03$; median, $0.11 ; n=115$ ). $\boldsymbol{E}$, Distribution of correlation coefficient of $0 \mathrm{~N} / \mathrm{OFF}$ responses (mean, $0.69 \pm 0.02 ;$ median

nasotemporally and $-10-50^{\circ}$ ventrodorsally in visual space. Stimulus sets included a blank condition in which the screen was at mean luminance. Responses to all such blank presentations were averaged to obtain the spontaneous firing rate.

To determine receptive field structures of SC neurons, $5^{\circ}$ light squares were flashed at different locations on either a $13 \times 13$ or $11 \times 11$ grid with $5^{\circ}$ spacing. The flashes stayed $\mathrm{ON}$ for $500 \mathrm{~ms}$ on a gray background and OFF for $500 \mathrm{~ms}$ between stimuli, and were repeated for at least five times for each grid location in a pseudorandom sequence. Average spike rate in response to flash onset and offset were calculated for each grid location after subtracting the spontaneous rate. The ON- and OFF-evoked spike rates on the grid were each fitted with a two-dimensional Gaussian distribution with independent SDs, $a$ and $b$, in the coordinate system defined by the axes of the response field, as shown in the following equation:

$$
G(x, y)=\frac{A}{2 \pi a b} \exp \left(\frac{x^{\prime 2}}{2 a^{2}}+\frac{y^{\prime 2}}{2 b^{2}}\right)
$$

where $x^{\prime}$ and $y^{\prime}$ are the polar transformations of space coordinates $x$ and $y$ at an angle $\theta$, along which the Gaussian distribution is oriented. The center of the Gaussian was determined as the location where the maximum response was observed. Consequently, two independently fitted ellipses describing the ON and the OFF subfields of the receptive field of a cell were obtained. The area enclosed by the fitted ellipse (with $a$ and $b$ as its semimajor and semiminor axes) was used to quantify the area covered by each subfield $\left(\right.$ Area $_{\text {on }}$ and Area $\left.{ }_{\text {off }}\right)$. The relative strengths and spatial relationship of the ON and OFF subfields were then quantified by response ratio, area ratio, overlap index (OI), and correlation coefficient. 
Response ratio was calculated with peak ON and OFF responses, $\left(R_{\text {on, } \max }-R_{\text {off,max }}\right) /\left(R_{\text {on, } \text { max }}+R_{\text {off,max }}\right)$, and area ratio was as follows: $\left(\right.$ Area $_{\text {on }}-$ Area $\left._{\text {off }}\right) /\left(\right.$ Area $_{\text {on }}+$ Area $\left._{\text {off }}\right)$. The overlap index (Schiller et al., 1976; Liu et al., 2009) incorporates the size of subfields as well as the closeness of their centers to indicate the degree of overlap between $\mathrm{ON}$ and OFF subfields: $\mathrm{OI}=\left(W_{1}+W_{2}-c\right) /\left(W_{1}+W_{2}+c\right)$, where $W_{1}$ and $W_{2}$ are the half-widths of the subfields measured along the line joining the subfield centers and $c$ is the distance between the ON and OFF subfield centers. An OI of 1 thus indicates complete overlap, whereas zero or negative OI, no overlap.

Correlation coefficient $(r)$ was a correlation measure between $\mathrm{ON}$ and OFF responses $\left(R_{\mathrm{ON}, i}\right.$ and $\left.R_{\mathrm{OFF}, i}\right)$ at each grid location $i$ and was calculated from raw spike rates independent of fitting (Priebe et al., 2004; Liu et al., 2009) as follows:

$$
r=\frac{\sum_{i=1}^{n}\left(R_{\mathrm{on}, i}-\overline{R_{\mathrm{on}}}\right)\left(R_{\mathrm{off}, i}-\overline{R_{\mathrm{off}}}\right)}{\sqrt{\sum_{i=1}^{n}\left(R_{\mathrm{on}, i}-\overline{R_{\mathrm{on}}}\right)^{2} \sum_{i=1}^{n}\left(R_{\mathrm{off}, i}-\overline{R_{\mathrm{off}}}\right)^{2}}} .
$$

Drifting sinusoidal gratings of $100 \%$ contrast were presented to probe selectivity for stimulus direction/orientation and spatial/temporal frequency tuning. The drifting direction was varied between 0 and $360^{\circ}(12$ steps, $30^{\circ}$ spacing), spatial frequency between 0.01 and $0.32 \mathrm{cpd}$ (6 logarithmic steps), and temporal frequency between 0.5 and $8 \mathrm{~Hz}$ ( 5 logarithmic steps). In any stimulus set, only two parameters were varied, either direction and spatial frequency or direction and temporal frequency. A temporal frequency of $2 \mathrm{~Hz}$ was used when probing for spatial frequency tuning and direction/orientation selectivity. When varying temporal frequencies, the preferred spatial frequency for each cell was first determined and used.

Each stimulus of given direction and spatial/temporal frequency (or a blank condition) was presented for $1.5 \mathrm{~s}$ in a pseudorandom order for four to six trials. The interval between stimuli was $0.5 \mathrm{~s}$. The response to a particular stimulus condition, $R$, was obtained by averaging the number of spikes over the $1.5 \mathrm{~s}$ stimulus duration, across all trials and subtracting the spontaneous rate. We determined the direction at which the response was the greatest when averaged over all spatial frequencies, and the preferred spatial frequency was the one that yielded the maximum response at this direction. Note cells that preferred 0.01 or $0.32 \mathrm{cpd}$ in our analyses might be tuned to even lower or higher spatial frequencies as no other values were tested.

A direction tuning curve was obtained for responses to all directions at the preferred spatial frequency. The preferred direction $\left(\theta_{\text {pref }}\right)$ was determined as the one that evoked maximum response. The depth of modulation was described using two parameters: (1) direction selectivity index $(\mathrm{DSI})=\left(R_{\text {pref }}-R_{\text {opp }}\right) /\left(R_{\text {pref }}+R_{\text {opp }}\right)$, where $\mathrm{R}_{\text {pref }}$ was the response at $\theta_{\text {pref }}$ and $R_{\text {opp }}$ at $\theta_{\text {pref }}+\pi$; and (2) orientation selectivity index (OSI) $=$ $\left(R_{\text {pref }}^{\prime}-R_{\text {orth }}\right) /\left(R_{\text {pref }}^{\prime}+R_{\text {orth }}\right)$, where $R_{\text {pref }}^{\prime}$ was the mean response of $R_{\text {pref }}$ and $R_{\text {opp }}$ (as $\theta_{\text {pref }}$ and $\theta_{\text {pref }}+\pi$ had the same orientation), and $R_{\text {orth }}$ was the mean response to the two directions orthogonal to $\theta_{\text {pref }}$. Note that the OSI was calculated differently from that in the studies by Niell and Stryker (2008), L. Wang et al. (2009), and B. S. Wang et al. (2010), where $R_{\text {pref }}$ was used instead of $R_{\text {pref }}^{\prime}$. The tuning curves were fitted with a sum of two Gaussians centered at $\theta_{\text {pref }}$ and $\theta_{\text {pref }}+\pi$ using the nlinfit function in Matlab (The MathWorks), and the tuning width was calculated as the half-width at half-maximum of the fitted curve above the baseline (Niell and Stryker, 2008).

Linearity of response to drifting gratings was calculated at the preferred direction and spatial frequency by first binning the response at $100 \mathrm{~ms}$ intervals (minus the spontaneous rate) and then applying a discrete Fourier transform to compute F1/F0, the ratio of the first harmonic (response at the drift frequency) to the mean response (Niell and Stryker, 2008).

For analyzing temporal frequency tuning, response magnitude was again calculated by averaging over the $1.5 \mathrm{~s}$ stimulus duration. The tuning curves were obtained by choosing the responses to all temporal frequencies at the preferred direction, which was determined as the one in which peak response was observed. The preferred temporal frequency was then determined without curve fitting. Note that the classification of cells preferring $0.5 \mathrm{~Hz}$ could be confounded by the fact that no lower
A

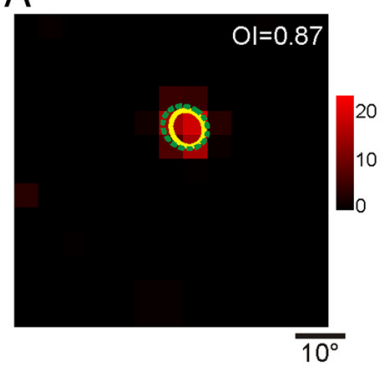

C

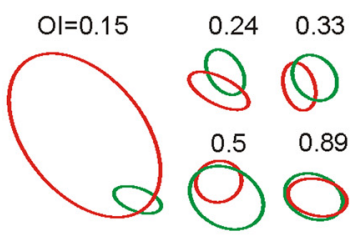

E

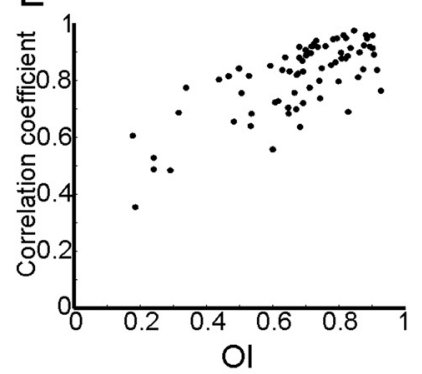

G

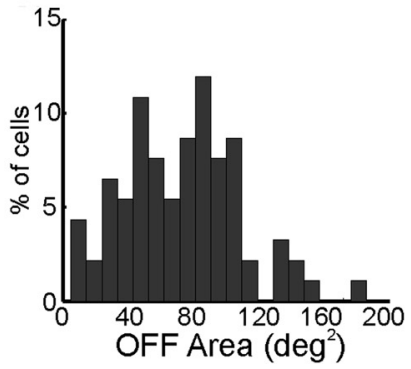

B
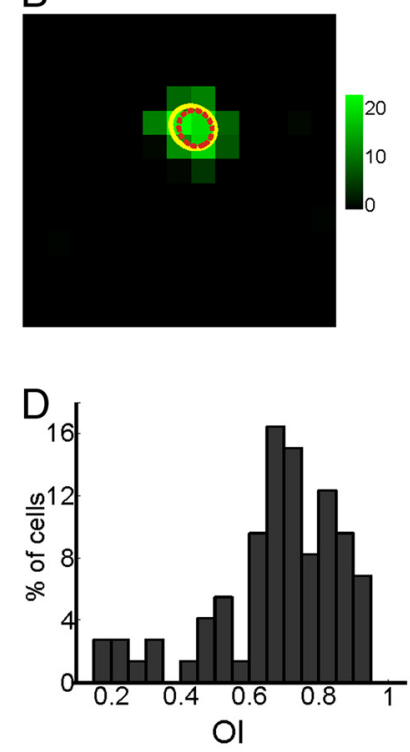

F

$\mathrm{H}$

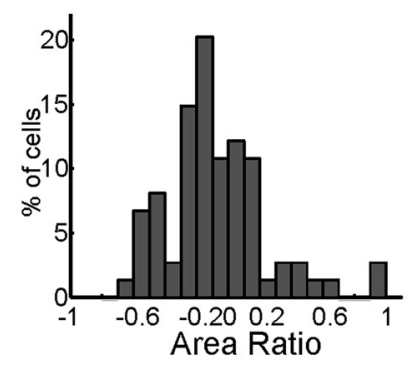

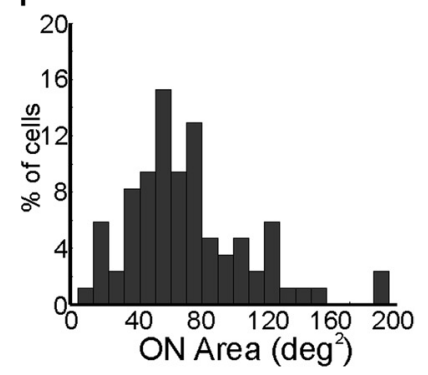

Figure 2. Overlapped ON and OFF subfields in the receptive field of SC neurons. $A, B, O N(A)$ and OFF $(\boldsymbol{B})$ responses of a $\mathrm{SC}$ neuron (same as in Fig. $1 B$ ) to flashing spots. The color scales represent response magnitude (spikes/second), with red for $\mathrm{ON}$ and green for $\mathrm{OFF}$. The yellow solid line on each panel is two-dimensional Gaussian fit of the response, and the dashed line is the fit of the opposite polarity, illustrating the large overlap of $\mathrm{ON}$ and $\mathrm{OFF}$ responses $(\mathrm{OI}=$ 0.87). C, Examples of SC receptive fields, with ON (red) and OFF (green) subfields and their OI shown above. $D$, Distribution of 01 (median, 0.71 ; mean, $0.68 \pm 0.02 ; n=73$ ). $E$, Correlation between 0 and $0 \mathrm{~N} / 0 \mathrm{FF}$ response correlation coefficient $\left(r^{2}=0.55 ; p<0.001 ; n=73\right) . \boldsymbol{F}, \mathbf{G}$, Distribution of the area of $O N(\boldsymbol{F})$ and $0 \mathrm{FF}(\boldsymbol{G})$ subfield. Note that the $x$-axes in both figures are cut off at $210 \mathrm{deg}^{2}$ to better illustrate the distributions (ON area, $107.5 \pm 14.9 \mathrm{deg}^{2}$ with median of $70.4 \mathrm{deg}^{2} ; n=85 ; 0$ FF area, $111.5 \pm 12.5 \mathrm{deg}^{2}$ with median of $\left.83.4 \mathrm{deg}^{2} ; n=92\right)$. $\boldsymbol{H}$, The distribution of $0 \mathrm{~N} / \mathrm{OFF}$ area ratio (mean, $-0.08 \pm 0.04$; median, $-0.12 ; n=73$ ).

values were tested and the gratings did not complete a full cycle within the stimulus duration.

Two types of stimuli were used to study the selectivity of SC neurons for stimulus size. First, circular light flashes of varying sizes $\left(2-30^{\circ}\right.$ in radius, eight steps on a linear scale) were centered on the receptive field determined using the flashing spot stimuli described above. Flashes of different sizes appeared $\mathrm{ON}$ for $500 \mathrm{~ms}, 1 \mathrm{~s}$, or $2 \mathrm{~s}$ and were followed by a blank screen of background luminance for the same duration. Responses 
were separated into ON and OFF depending on their occurrence either after flash onset or offset. The preferred size was the size at which maximal response was obtained. Second, sinusoidal gratings drifting along different directions were presented in circular patches of varying sizes $\left(2-32^{\circ}\right.$ in radius; five steps at a logarithmic scale). The gratings were presented at the preferred spatial frequency of the cell (as determined by full screen stimuli, as above), temporal frequency of $2 \mathrm{~Hz}$ and centered at the receptive field (determined by flashing spot stimuli). The preferred direction was the one at which the peak response was observed and the size of the patch at the peak response was determined as the preferred size. Note that a complete cycle of gratings might not be contained by the small patches at any given time, but instead drifted through them for three full cycles during the stimulus duration.

Juxtacellular labeling. Juxtacellular labeling was performed to reveal the morphology of the recorded SC neurons in a number of experiments. In these experiments, the overlaying tissues were removed by aspiration to expose the SC, facilitating the insertion of borosilicate glass pipettes (tip diameter of $0.5-4 \mu \mathrm{m}$; filled with $1-4 \%$ biocytin in $1 \mathrm{M} \mathrm{NaCl}$ ). After isolating a single unit and recording its visually evoked responses, the pipette was further advanced toward the cell to achieve juxtacellular configuration, which was confirmed by the ability to drive the firing of the cell with positive current injection (Pinault, 1996). Biocytin was then electrophoresed to label the recorded cell by applying positive current steps (1-5 nA, $2 \mathrm{~Hz}, 50 \%$ duty cycle) through a MultiClamp 700B amplifier (Molecular Devices). Spike shape and amplitude were closely monitored throughout recording, pipette advancing, and current injection to ensure that only one single neuron was recorded and subsequently labeled. After 15-45 min of current injection, the mice were allowed to survive for at least $2 \mathrm{~h}$ before perfusion with $4 \%$ paraformaldehyde (Electron Microscopy Science). The brain was then removed and cut into $100 \mu \mathrm{m}$ parasagittal sections with a vibratome. The labeled cells were revealed by visualizing biocytin with streptavidin-Alexa Fluor 488 conjugate (Invitrogen), following a published protocol (Wilson and Sachdev, 2004). Images were taken under a Zeiss fluorescent microscope. All labeled neurons, which were recorded with the pipette tips within $300 \mu \mathrm{m}$ below the SC surface, were confirmed to be within the stratum griseum superficiale (SGS).

The visually evoked responses of individually labeled cells in these experiments were analyzed to reveal their receptive field properties. Because of the low rate of successful juxtacellular labeling, we included in our analysis cells whose flash-induced responses could not be appropriately fitted. Consequently, we simply counted the number of grid points where flashes evoked responses to quantify their receptive field sizes. For the same reason, we combined responses to drifting gratings and sweeping bars (L. Wang et al., 2009) in analyzing the orientation/direction selectivity of these labeled cells.

Statistical analysis. All values were presented as mean \pm SEM. Statistical analyses and graph plotting were done with Prism (GraphPad Software) and Matlab (The MathWorks). In figures, ${ }^{\star} p<0.05,{ }^{* *} p<0.01$, and ${ }^{* *} p<0.001$.

\section{Results}

\section{Mouse SC neurons have overlapped ON/OFF subregions in} their receptive fields

To determine receptive field structure of mouse SC neurons, we recorded their single-unit activity in response to a small spot
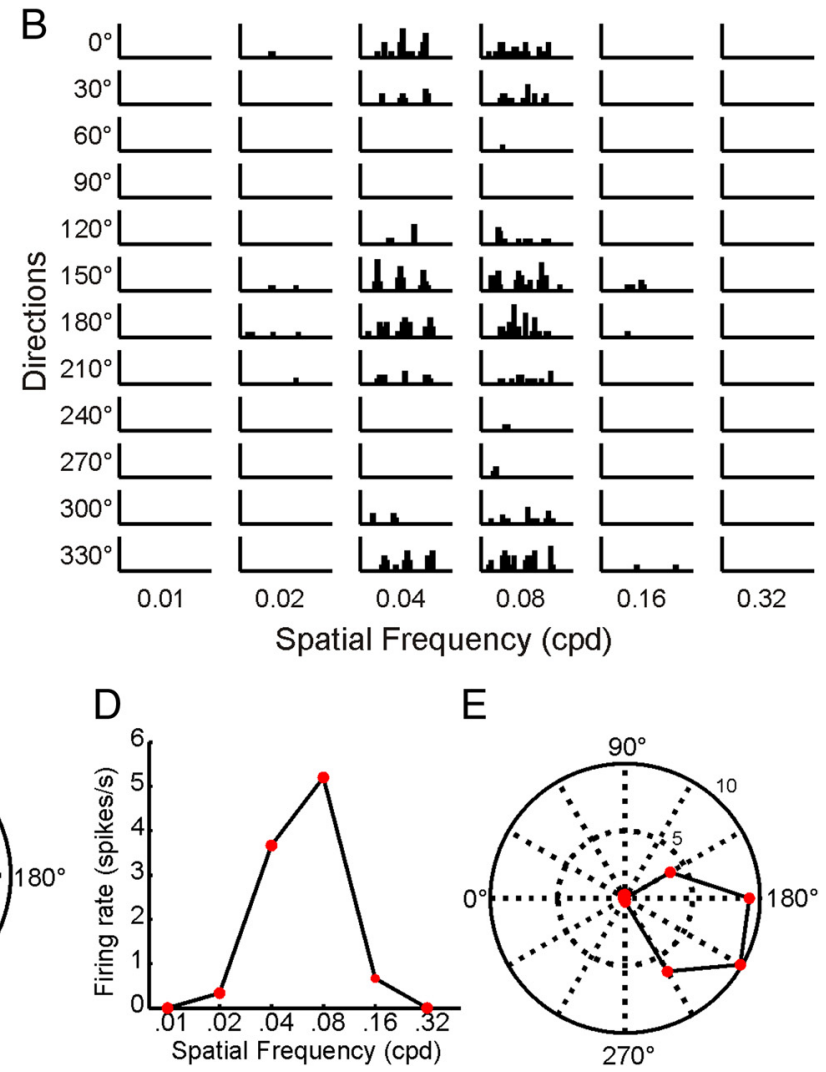

Figure 3. SC responses evoked by drifting gratings. $A$, Sinusoidal gratings (top panel) drifted perpendicular to their orientations Dientation selectivity. $\boldsymbol{D}$, Spatial frequency tuning curve of the same cell at its preferred direction. $\boldsymbol{E}$, Tuning curve of a directionflashed at different positions in the visual field (Fig. 1A). Such stimuli were effective in driving almost all recorded superficial SC neurons ( $n=115$ of 122, 26 mice), when appearing within their receptive fields (Fig. $1 \mathrm{~B}$ ). Most cells responded to both onset and offset of the flashes at the same visual field locations (Fig. 1A,B). We thus separated the stimulus-evoked spikes into ON and OFF responses at each location to quantify their relationship. The vast majority of SC neurons $(90.4 \% ; n=104$ of 115$)$ showed both ON and OFF responses, whereas only $6.1 \%$ showed only ON ( $n=7$ of $115)$ and $3.5 \%$ ( $n=4$ of 115 ) OFF responses (Fig. 1C), consistent with previous studies of the mouse SC (Dräger and Hubel, 1976; Chandrasekaran et al., 2007). We calculated the average ON and OFF firing rates to each stimulus position and then computed a response ratio to measure the relative strength between the strongest responses, with positive reflecting stronger $\mathrm{ON}$ and negative, stronger OFF (see Materials and Methods). The peak of the response ratio histogram fell around zero (Fig. 1D) (median, 0.11 ; mean, $0.11 \pm 0.03 ; n=115$ ), indicating that most neurons had similar maximum response to flash onset and offset. We next calculated Pearson's correlation coefficient between $\mathrm{ON}$ and OFF responses to compare their spatial distribution (see Materials and Methods). This coefficient was close to 1 for most cells (Fig. 1E) (median, 0.78; mean, $0.69 \pm 0.02 ; n=$ 114 ), indicating that $\mathrm{ON}$ and $\mathrm{OFF}$ responses had similar magnitude at the same locations in the visual field. Few cells had negative correlation coefficients ( $n=4$ of 114) (Fig. $1 E$ ), as would be seen for cortical simple cells that have spatially offset ON and OFF subfields (Liu et al., 2009). 
To further quantify the spatial overlap between ON and OFF responses, we calculated an OI, which measures the separation between the ON and OFF peak responses in relationship to the sizes of both subfields (see Materials and Methods). For individual cells, we fitted the ON and OFF responses each with a twodimensional Gaussian (Fig. 2A,B, yellow solid lines; with $A$ showing ON response and $B, \mathrm{OFF}$ ) and calculated the OI for well fitted cells that had both ON and OFF responses. All of these cells had positive OI (median, 0.71; mean, $0.68 \pm 0.02 ; n=73$ ) (Fig. $2 C, D)$ and the vast majority $(85 \% ; n=62$ of 73 ) were $>0.5$, confirming large overlap between ON and OFF subfields. As expected, the SC neurons with higher OI had stronger correlation between $\mathrm{ON}$ and OFF responses (Fig. 2E).

Fitting the subfields using Gaussians also allowed us to quantitatively describe the size of the ON and OFF subfields. Overall, the ON (107.5 $\pm 14.9 \mathrm{deg}^{2}$; median, $70.4 \mathrm{deg}^{2} ; n=$ 85) (Fig. $2 F)$ and OFF subfields $\left(111.5 \pm 12.5 \mathrm{deg}^{2}\right.$; median, $83.4 \mathrm{deg}^{2} ; n=92$ ) (Fig. $2 G$ ) were similar in size. For individual cells, we compared the relative size of the two subfields by calculating an area ratio (see Materials and Methods). Although slightly more neurons had negative values (mean, $-0.08 \pm 0.04$; median, $-0.12 ; n=73)$, the area ratio clustered near zero (Fig. $2 \mathrm{H}$ ), confirming that the ON and OFF subfields were mostly similar in the same neurons.

Mouse SC neurons show orientation and direction selectivity To study the tuning properties of SC neurons, we presented drifting sinusoidal gratings of varying moving directions (12 steps at $30^{\circ}$ spacing) and spatial frequencies $(0.01-0.32$ cycles per degree) (Fig. $3 A, B$ ). A wide range of response selectivity was observed. Like in rats (Girman and Lund, 2007; Prévost et al., 2007), we found that some SC neurons displayed high orientation selectivity to the gratings. The neuron in Figure $3 B-D$, for example, responded similarly to gratings of the same orientation but drifting along opposite directions (e.g., 0 vs $180^{\circ}$, and 330 vs $150^{\circ}$ ). In contrast, some neurons were highly selective for moving direction, sometimes displaying a complete preference for one direction over its opposite (Fig. 3E). Other neurons, however, responded similarly to all directions of motion. To quantify the degree of direction/orientation selectivity, we calculated a DSI and an OSI for all the neurons that responded to the drifting gratings $(n=125$ of 131$)$. Overall, the mean DSI was $0.39 \pm 0.03$ $(n=125)$ (Fig. $4 B)$ and $30 \%$ of cells $(n=37$ of 125$)$ had DSI $\geq$ 0.5 , a $3: 1$ ratio for the preferred direction over its opposite. We also examined the relationship between the DSI and preferred directions of individual SC neurons and found no bias in preference toward certain directions (Fig. 4A). This result differs from a previous study, which reported that the majority of directionselective SC neurons in the mouse preferred upward motion (Dräger and Hubel, 1976).

To calculate the OSI, we averaged the responses evoked by the preferred direction and its opposite direction to obtain the response to the preferred orientation (see Materials and Methods). Across the population, $33 \%$ of SC cells $(n=41$ of 125$)$ were found to have OSI $\geq 0.5$ (Fig. $4 C$ ) (with mean of $0.41 \pm 0.03$ ). Importantly, a cell with high OSI could in fact be directionselective because of how the OSI was calculated. For example, the cell shown in Figure 3E, which was clearly direction selective instead of orientation selective, had OSI of 1 because of its zero response to the directions orthogonal to the preferred one. We therefore examined the distribution of the DSI in the context of different OSIs (Fig. 4C). In the group of cells with OSI $\geq 0.5(n=$ 41), 22 cells had DSI $<0.5$, indicating that many cells in this
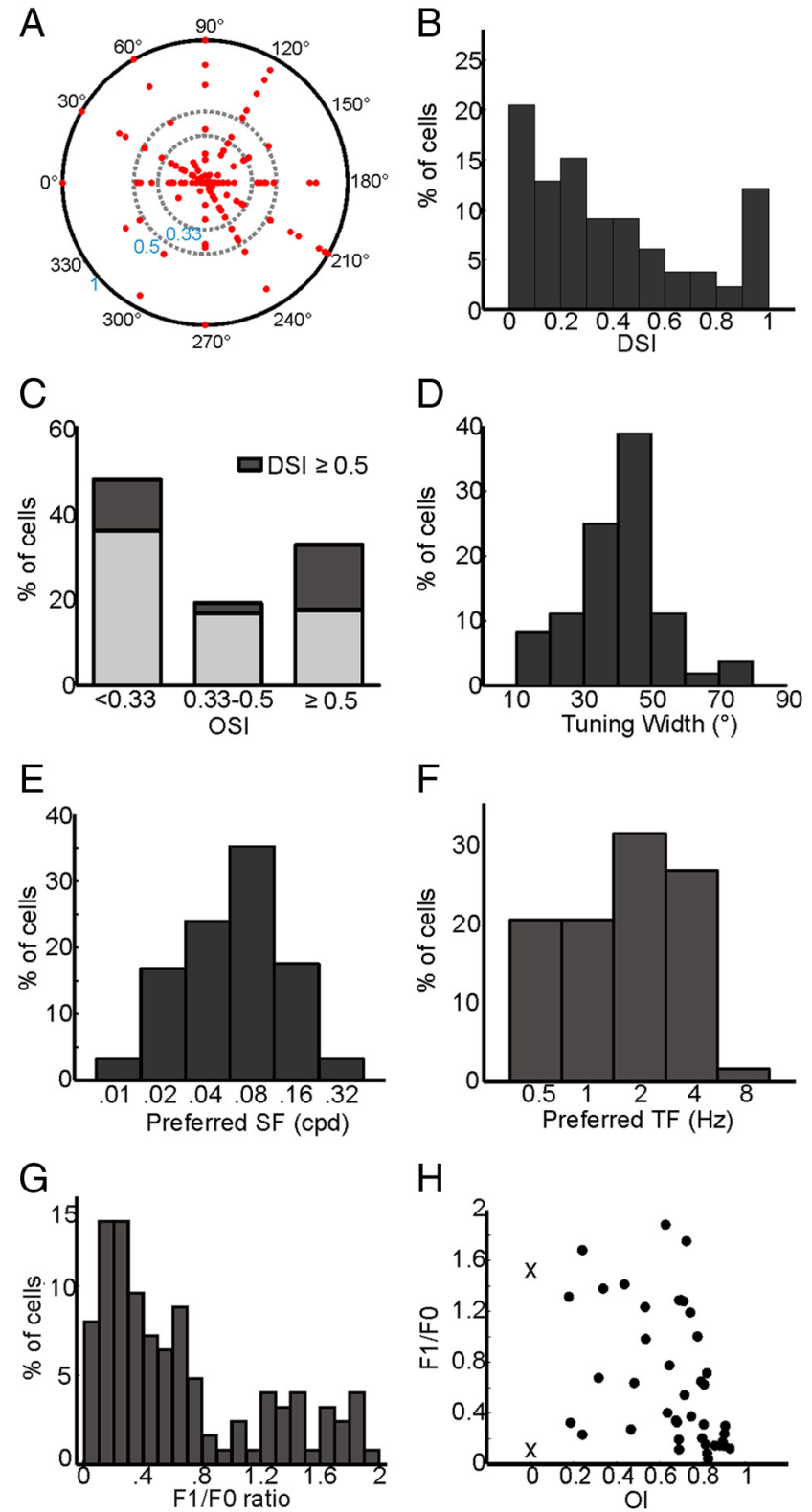

Figure 4. Population analysis of grating-evoked responses. A, Polar plot of DSI (radii from origin) and preferred directions (angles). The outer circle represents DSI value of 1 , the middle one of 0.5 , and the inner one of 0.33 . $B$, Distribution of DSI (mean, $0.39 \pm 0.03$; median, 0.28 ; $n=125$ ). Note that a substantial fraction of neurons had DSI near 1. C, Distribution of highly direction-selective cells (DSI $\geq 0.5$ ) in groups of different OSI values. $\boldsymbol{D}-\boldsymbol{F}$, Distributions of tuning width (mean, $40.9^{\circ} \pm 1.3^{\circ} ;$ median, $42.8^{\circ} ; n=108$ ) (D), preferred spatial frequency $(n=125)(\boldsymbol{E})$, and temporal frequency $(n=64)(\boldsymbol{F}) . \boldsymbol{G}$, The F1/F0 ratio of $S C$ neurons shows a bimodal distribution, with most $(n=93$ of 125$)<1$. $\boldsymbol{H}$, Correlation between $\mathrm{F} 1 / \mathrm{F} 0$ ratio and 0 I of individual cells $\left(r^{2}=0.17 ; p<0.01 ; n=41 ;\right.$ black dots). Note that cells that only responded to $\mathrm{ON}$ or $\mathrm{OFF}$ were added to the plot (" $\mathrm{x}$ " symbols), with their $0 \mathrm{l}$ assigned to 0 .

group were truly orientation selective. The fact that some direction-selective cells had low OSI (Fig. 4C) suggested that these cells were tuned to a broad range near their preferred directions. Indeed, we found that the tuning width (half-width at the half-maximum) (see Materials and Methods) of all SC neurons were quite large on average, with mean of $40.9^{\circ} \pm 1.3^{\circ}$ and median of $42.8^{\circ}(n=108)$ (Fig. $\left.4 D\right)$.

As shown by the example in Figure 3D, SC neurons responded preferentially to particular spatial frequencies. Almost all SC neurons were tuned to the midrange of the tested spatial frequencies, 
with their preferred values ranging from 0.02 to $0.16 \mathrm{cpd}$ (Fig. $4 E$ ). We also investigated SC temporal frequency tuning by presenting sinusoidal gratings at the preferred spatial frequency of individual neurons. Most cells (97\%; $n=62$ of 64 ) preferred temporal frequencies between 0.5 and $4 \mathrm{~Hz}$ (Fig. $4 F$ ). The highest percentage $(34 \%)$ of cells preferred $2 \mathrm{~Hz}$, the value used in the experiments to examine direction selectivity and spatial tuning.

Using sinusoidal gratings, we were able to examine the linearity of SC neurons (Skottun et al., 1991). A number of SC cells showed periodic modulation of firing rate at the drifting frequency of the gratings $(2 \mathrm{~Hz}$, as seen for example at 0.04 cpd in Fig. $3 B$ ), indicating that they were "linear." This linearity can be quantified by calculating an F1/F0 ratio, the ratio of the response at the drifting frequency to the mean response (Niell and Stryker, 2008). An F1/F0 value $<1$ is commonly considered as a nonlinear response, and $>1$ as linear (Skottun et al., 1991). At the preferred spatial frequencies, the F1/F0 ratio of SC neurons displayed a bimodal distribution (Fig. 4G), with most cells $<1$ ( $n=93$ of $125 ; 74 \%)$. This distribution is quite different from that in the mouse visual cortex, where linear and nonlinear cells are approximately equal in numbers (Niell and Stryker, 2008) (see below). The relatively small population of linear neurons in the SC appeared to be consistent with the fact that most SC cells had spatially overlapped $\mathrm{ON}$ and OFF subfields (Fig. 2). We therefore examined the relationship between F1/F0 ratio and the OI determined by the flashing spot stimuli. There was indeed a significant correlation between the two $\left(r^{2}=0.17\right.$; $p<0.01 ; n=41$ ) (Fig. $4 H$ ), with cells of greater OI (more overlapped subfields) having lower F1/F0 (less linear). However, the F1/F0 ratio for a given OI varied widely, occupying almost the whole range. In fact, even for the cells that responded to ON or OFF stimulus only, very different F1/F0 values were observed (Fig. $4 H$ ). The above analyses therefore indicate that linearity in the SC is not solely determined by the spatial segregation of $\mathrm{ON}$ and OFF subfields. Furthermore, we found that many SC neurons displayed greater F1/F0 values at the spatial frequency immediately below their preferred ones $(0.77 \pm 0.05$ vs $0.65 \pm 0.05)$ (Fig. 3B). A small number of nonlinear cells even became linear at the lower spatial frequency ( $n=17$ of 125 compared with 4 cells switching from linear to nonlinear), similar to what was reported for cortical complex cells (Movshon et al., 1978a).

\section{Mouse SC neurons prefer visual stimulus of certain size}

We next determined how stimulus size influences firing properties in the mouse SC, as size selectivity is an important tuning property for SC neurons in all species studied (Binns and Salt, 1997b; Razak and Pallas, 2006). To do this, we used two types of visual stimuli: flashes and drifting gratings displayed in circles of different sizes that were centered on the receptive field.
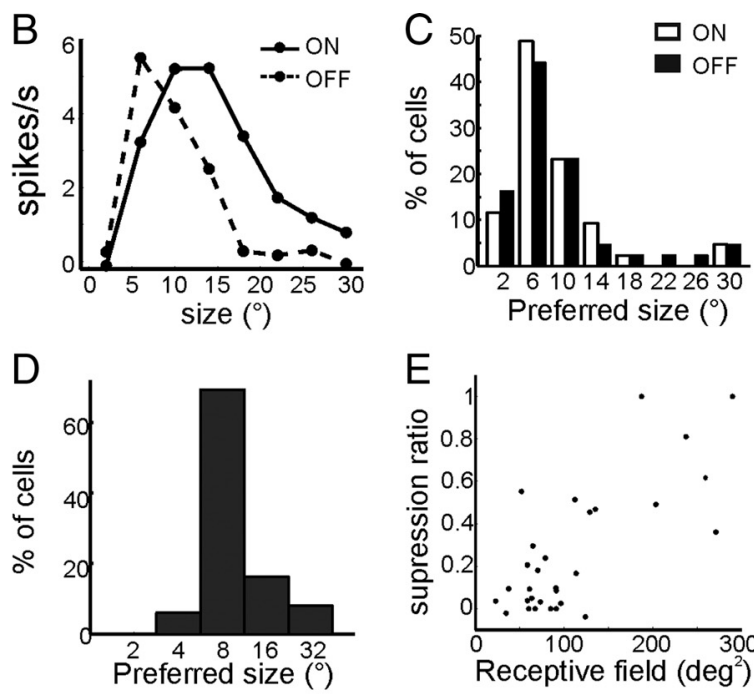

$\mathrm{F}$
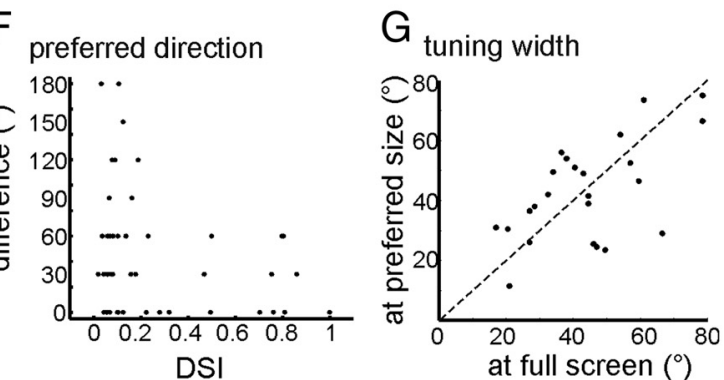

Figure 5. The preference of SC neurons for stimulus size. A, PSTHs of an example neuron in response to flashing circles of preferred sizes to drifting gratings $(n=49)$. $\boldsymbol{E}$, Ratio of the response evoked by the largest grating to that evoked by the preferred response to optimally sized and full-field gratings is plotted against the DSI at the preferred size $(n=49)$. $\mathbf{G}$, Similar tuning widths in response to gratings at the preferred size and at full screen $\left(r^{2}=0.35 ; p<0.01 ; n=24\right)$.

In response to flashes of increasing sizes, SC neurons displayed selectivity for optimally small stimuli. The neuron shown in Figure $5 A$, for example, responded robustly to both $\mathrm{ON}$ and OFF flashes of 6 and $10^{\circ}$, again indicating the overlap of $\mathrm{ON}$ and OFF subfields. Both ON and OFF responses decreased with bigger flashes (Fig. $5 A, B$ ), presumably suppressed by surround inhibition (Binns and Salt, 1997b). For each neuron, we calculated a ratio of the response evoked by the largest flash (ON and OFF together) to its maximum response. This ratio was near zero for most neurons as they were completely suppressed by the bigger stimulus (median, 0.02; mean, $0.09 \pm 0.03 ; n=43$ ), and some even had negative values as their firing rate fell below the spontaneous rate in response to the large flash ( $30^{\circ}$ in radius).

Across population, $\mathrm{ON}$ and OFF responses showed very similar distributions of preferred sizes (Fig. 5C), even though the preferred size could be different for the same cells (Fig. 5B). Overall, most SC neurons preferred flashes with the radius of $6-10^{\circ}$, similar to the range of receptive field areas obtained through flashing spot mapping (Fig. $2 F, G$ ). SC neurons displayed a similar selectivity for stimulus size in response to drifting gratings of varying sizes (Fig. 5D), but the degree of suppression was smaller compared with the flashes (Fig. 5E). Interestingly, neurons with smaller receptive fields were suppressed more by the larger stimulus (Fig. $5 E)(p<0.001 ; n=30)$. We next examined whether the tuning properties determined by full screen gratings were similar to those in response to the stimulus of optimal size. Even 

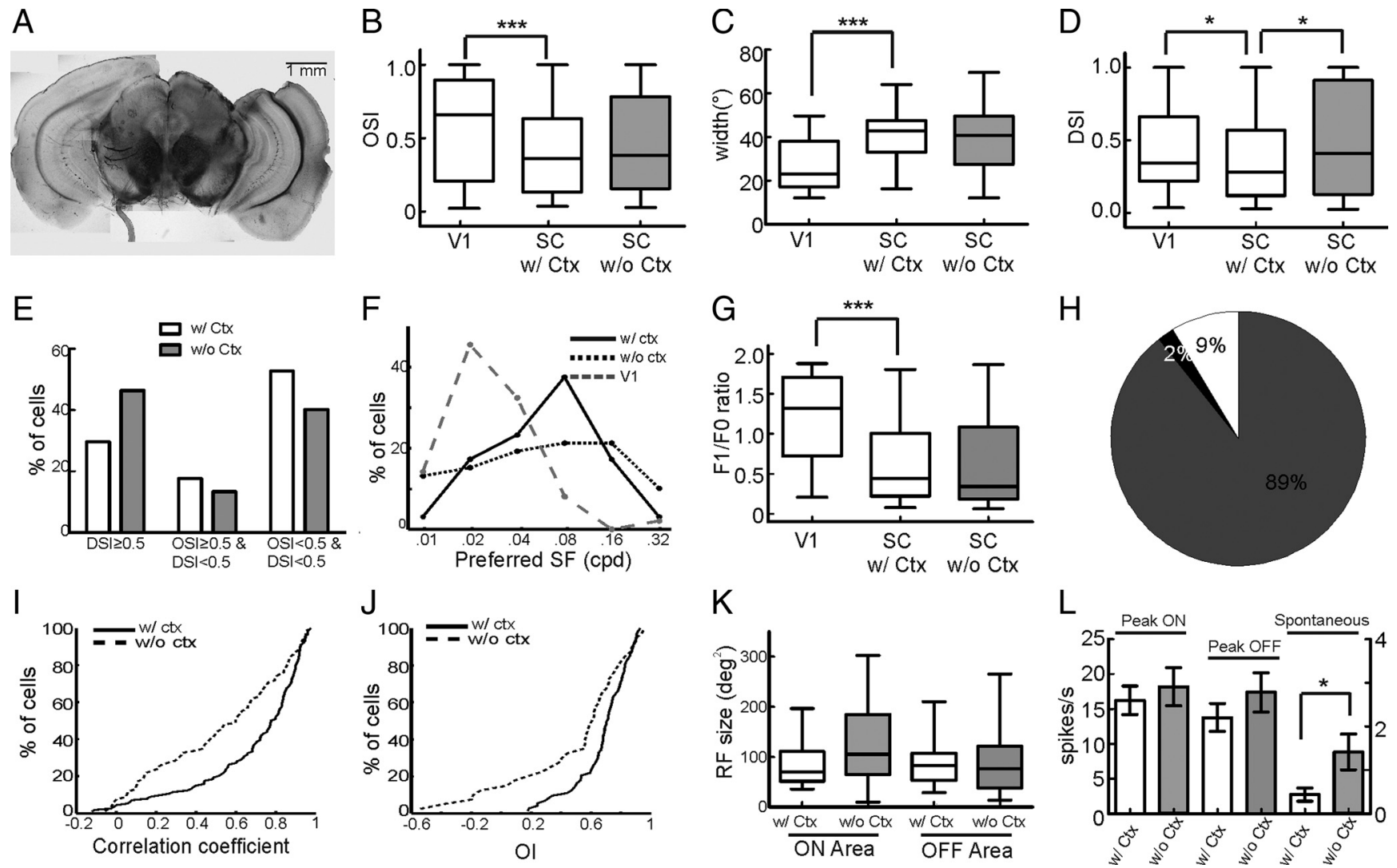

Figure 6. Cortical influence on SC response properties. $\boldsymbol{A}$, A coronal section showing the extent of cortical lesion. $\boldsymbol{B}$, Box plots of OSI in V1 ( $n=120)$, normal SC (SC w/ Ctx, $n=125)$ and $S C$ without cortical projections (SC w/0 Ctx, $n=112$ ). The ends of the plots represent 5th and 95th percentiles (same below unless otherwise noted). V1 cells are more orientation-selective than in $\mathrm{SC}(p<0.001)$, and removing cortex has no effect on SC selectivity $(p=0.49)$. C, Tuning width of the three groups $(\mathrm{V} 1, n=92 ; \mathrm{SC} / \mathrm{Ctx}, n=108 ; \mathrm{SC}$ $\mathrm{w} / 0 \mathrm{Ctx}, n=90)$. D, DSI of the three groups (V1, $n=120 ; \mathrm{SC} \mathrm{w} / \mathrm{Ctx}, n=125 ; \mathrm{SC} / 0 \mathrm{Ctx}, n=112)$. $\boldsymbol{E}$, Distribution of direction-selective cells (DSI $\geq 0.5)$, orientation-selective cells $(0 S I \geq 0.5$ and DSI $<0.5)$, and others (OSI $<0.5$ and DSI $<0.5)$ in the SC with and without cortex. $F$, Distribution of the preferred spatial frequency $(\mathrm{V} 1, n=98 ; S C \mathrm{w} / \mathrm{Ctx}, n=125$;

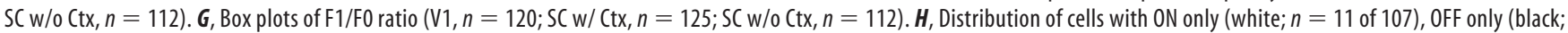
$n=4$ of 107), and $0 \mathrm{~N}-0 \mathrm{FF}$ responses (gray; $n=92$ of 107) in the absence of cortical input. I, Cumulative distribution of correlation coefficient in the two conditions (SC $\mathrm{W} / \mathrm{Ctx}, n=114$; $\mathrm{SC} \mathrm{w} / 0 \mathrm{Ctx}, n=92 ; p<0.001)$. J, Cumulative distribution of Ol (SC w/ Ctx, $n=73 ; \mathrm{SC} / 0 \mathrm{Ctx}, n=40 ; p<0.05$ ). $K$, Removing cortex does not change ON, OFF subfield areas of SC neurons. The ends of the box plots represent 10th and 90th percentiles. $L$, Evoked and spontaneous firing rate of $S C$ neurons in the presence and absence of cortical input. ${ }^{*} p<0.05$, ${ }^{* *} p<0.01$, and ${ }^{* * *} p<0.001$.

though many cells had different preferred directions at the two sizes, the larger differences were limited to the cells with low DSI (Fig. $5 F$ ), for which the preferred direction was essentially meaningless. For highly selective cells, the difference was mostly within the range of $30^{\circ}$, the resolution we used in examining direction selectivity. In addition, the tuning widths of most selective cells were also similar at the two conditions (Fig. $5 G$ ), indicating SC tuning properties were mostly independent of stimulus size.

\section{Some, but not all, SC tuning properties are influenced by cortical inputs}

Mouse visual cortex is a well established model in studying experience-dependent development (Hensch, 2005), and more recently, receptive field properties (Niell and Stryker, 2008, 2010; Andermann et al., 2010). Because the superficial SC receives retinotopically organized inputs from V1 (Bereshpolova et al., 2006; Triplett et al., 2009), cortical neurons could modulate the response properties of SC neurons. To test this, we first compared cortical and collicular responses under the same recording conditions and then determined the effect of cortical lesion (Fig. 6A) on SC receptive fields.

Like in other species, V1 neurons in the mouse are highly orientation selective (Niell and Stryker, 2008; B. S. Wang et al.,
2010). When compared with collicular neurons, mouse V1 neurons showed a greater degree of orientation selectivity, displaying higher OSI (Fig. 6B) $(p<0.001$, Kolmogorov-Smirnov test; same below, unless otherwise indicated) and narrower tuning width (Fig. 6C) $(p<0.001)$. To test whether orientation selectivity in the SC could be derived from cortical inputs, we studied $\mathrm{SC}$ orientation tuning after removing V1 (Fig. $6 B, C$ ). No significant difference was observed for either OSI ( $p=0.49$ ) or tuning width ( $p=0.33$ ), indicating that the orientation selectivity in the SC must emerge from retinocollicular and/or intracollicular circuitry. Interestingly, the DSI of SC neurons was found to be greater in the absence of cortical input (Fig. $6 D)(p<0.05)$, even though cortical neurons were slightly more selective than SC neurons ( $p<$ 0.05 ). We further confirmed these observations by showing that cortical lesion increased the percentage of highly direction-selective cells (DSI $\geq 0.5$ ) (Fig. $6 E$ ), but did not change that of orientationselective cells (OSI $\geq 0.5$ and DSI $<0.5$ ). The effect of removing V1 input was also seen for spatial frequency tuning, where the distribution of preferred spatial frequency was altered in the absence of cortical input (Fig. $6 F)\left(p<0.001, \chi^{2}\right.$ test). In particular, slightly more cells preferred to 0.16 and $0.32 \mathrm{cpd}$, consistent with the result that $\mathrm{V} 1$ neurons are tuned to lower spatial frequencies compared with the SC (Fig. 6F) (Niell and Stryker, 2008). 
Similar percentage of ON, OFF, and ON-OFF cells were found in the SC on cortical lesion (Fig. $6 H$ ) ( $p=0.17$ compared with normal, $\chi^{2}$ test), but the spatial overlap between ON and OFF subfields became weaker as quantified by both correlation coefficient (Fig. 6I) $(p<0.001)$ and overlap index (Fig. $6 J)(p<$ $0.05)$. No significant difference was observed in receptive field size (Fig. $6 \mathrm{~K}$ ), although the ON subfields showed a trend of increase ( $p=0.07$ for ON area, $p=0.95$ for OFF area; $t$ test). No difference was seen in the evoked firing rates between the two conditions, whereas the spontaneous rate was higher on cortical lesion (Fig. $6 \mathrm{~L}$ ). Finally, we examined cortical influence on the linearity of collicular responses. More V1 neurons were linear, compared with that in the SC $(p<0.001)$ (Fig. $6 G)$. Removing cortical inputs, however, did not change linearity in the SC $(p=$ 0.19 ) (Fig. 6G), despite a decrease in overlap between ON and OFF subfields. This is consistent with the result shown in Figure $4 H$ that linearity in the SC may not simply come from the spatial segregation of ON and OFF subfields.

Together, these results indicate that SC neurons show very different tuning properties from V1 neurons and that some, but not all, of the tuning properties are influenced by cortical inputs.

\section{Visual experience plays a limited role in the development of $S C$ response properties}

Much work has been done to assess the role of visual experience in the development of retinal and visual cortical functions. For example, rearing mice in complete darkness from birth to adulthood is known to decrease cortical orientation selectivity (Fagiolini et al., 2003) but has no effect on direction selectivity in the retina (Elstrott et al., 2008). Given that the SC is heavily innervated by both structures, we were interested in whether visual deprivation affects $\mathrm{SC}$ receptive fields in the mouse.

In mice dark-reared (DR) from birth to approximately postnatal day 60 , when receptive field properties have normally matured, we found that more SC neurons had ON only responses than in the normally reared (NR) controls (Fig. 7A) $(n=14$ of 71 in DR; $p<0.001, \chi^{2}$ test). No significant difference was observed for the area of ON and OFF subfields between DR and NR animals, although the OFF subfields showed a trend of decrease (Fig. $7 B$ ). For neurons with both well fitted ON and OFF subfields, their overlap index did not change either (Fig. 7C) $(n=29 ; p=$ 0.81 ), suggesting that the convergence of ON/OFF inputs to the $\mathrm{SC}$ does not require visual experience. Interestingly, SC neurons in the DR mice were tuned to higher spatial frequencies when tested with drifting gratings (Fig. $7 D)\left(p<0.001, \chi^{2}\right.$ test). However, dark rearing did not change orientation or direction selectivity in the SC (Fig. $7 E, F$ ), unlike its effect on cortical neurons (Fagiolini et al., 2003). Overall, our experiments suggest that long-term visual deprivation during development only alters limited aspects of receptive field properties in the SC.

\section{Response properties of different types of superficial SC neurons}

The above experiments revealed that individual superficial SC neurons have diverse response properties. We wanted to determine whether such diversity came from different subtypes of SC neurons or from different responses within the same subtypes. As an initial attempt to examine cell type-specific responses in the SC, we performed juxtacellular labeling to reveal the morphology of neurons after recording their visually evoked responses (see Materials and Methods).

Using this method, we were able to identify 22 individually labeled superficial SC neurons ( $n=16$ mice). Based on their
A
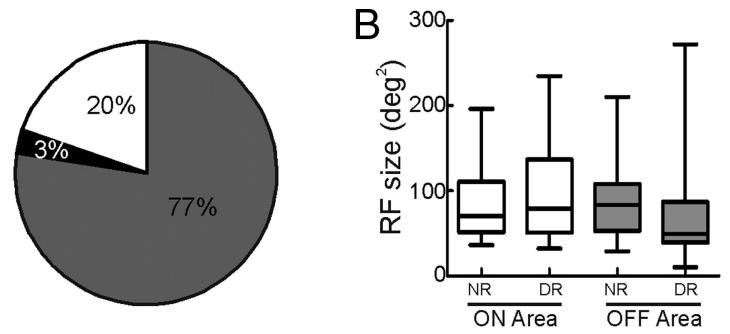

C

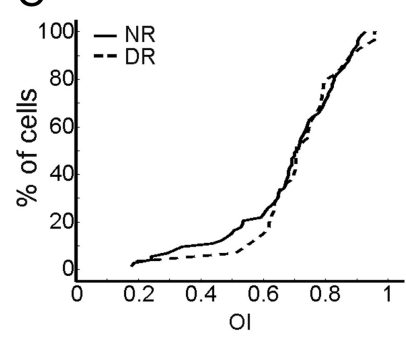

D

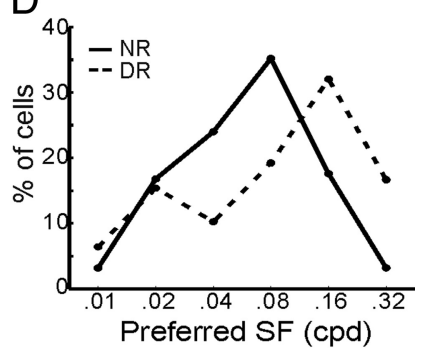

$\mathrm{E}$

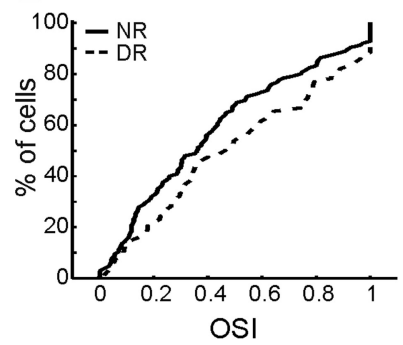

F

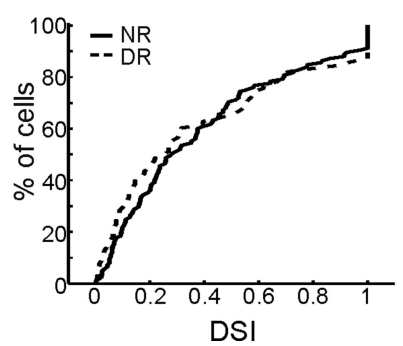

Figure 7. SC responses in the absence of visual experience during development. $\boldsymbol{A}$, Distribution of cells with $0 \mathrm{~N}$ only (white; $n=14$ of 71), OFF only (black; $n=2$ of 71), and $0 N-0 F F$ responses (gray; $n=55$ of 71 ) in the $S C$ after dark rearing from birth to the day of recording (approximately postnatal day 60 ). B, Dark rearing does not change 0N, OFF subfield size ( $p=0.95$ for $0 \mathrm{~N} ; p=0.57$ for $0 \mathrm{FF}, t$ test). The ends of the box plots represent 10th and 90th percentiles. C, Cumulative distribution of overlap index in NR $(n=73)$ and DR $(n=29)$ cells. No significant difference is found $(p=0.81)$. D, Distribution of the preferred spatial frequency in the SC of NR $(n=125)$ and DR $(n=78)$ mice. The distribution is shifted to higher spatial frequency in $\mathrm{DR}\left(p<0.001, \chi^{2}\right.$ test). $\boldsymbol{E}$, $\boldsymbol{F}$, Cumulative distribution of OSI $(\boldsymbol{E})$ and DSI $(\boldsymbol{F})$ in the two conditions. No significant difference is seen for either OSI ( $p=0.15)$ or DSI ( $p=0.44$ ).

similar morphology (Langer and Lund, 1974; Tokunaga and Otani, 1976), we grouped seven as putative narrow field vertical (NFV) cells (supplemental Table 1, group 1, available at www. jneurosci.org as supplemental material). Four cells appeared to be putative wide field vertical (WFV) cells (supplemental Table 1, group 2, available at www.jneurosci.org as supplemental material). Both NFV and WFV cells are known glutamatergic neurons that project to intermediate layers in the SC and other subcortical areas (Lee et al., 2001). We also labeled three horizontal cells (supplemental Table 1, group 3, available at www.jneurosci.org as supplemental material), which are GABAergic interneurons with horizontally extended dendrites (Lee et al., 2001). The remaining eight cells were difficult to classify using the current method but were clearly different from the other three classes. We thus grouped them into "others" (supplemental Table 1, group 4, available at www.jneurosci.org as supplemental material). These may include marginal cells, stellate cells, and piriform cells, all of which are likely to be inhibitory (Lee et al., 2001).

Shown in Figure $8 \mathrm{~A}$ is a putative NFV neuron, whose cell body was located $\sim 100 \mu \mathrm{m}$ below the SC surface and dendritic field extended vertically. Its dendritic tree was at most $100 \mu \mathrm{m}$ in 
A

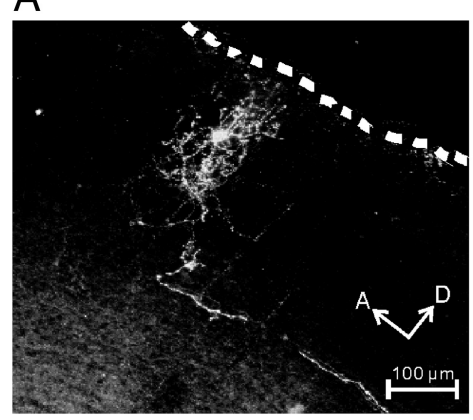

D

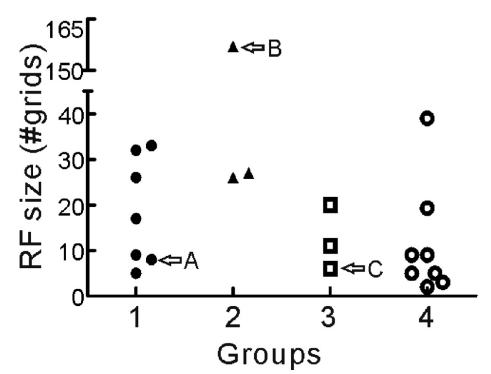

B

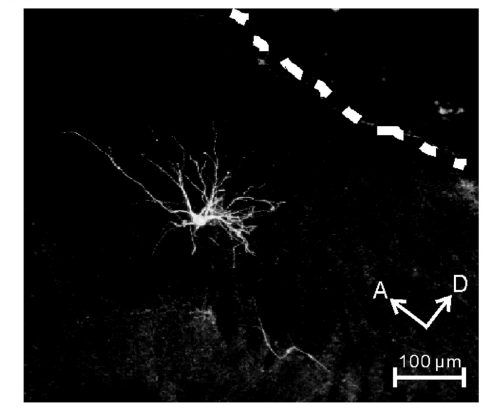

E

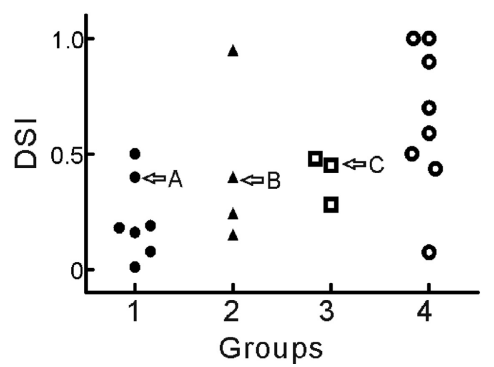

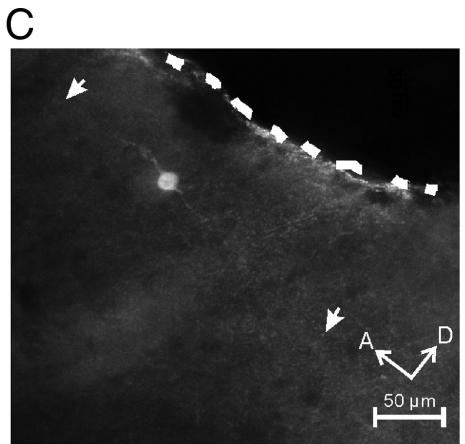

F

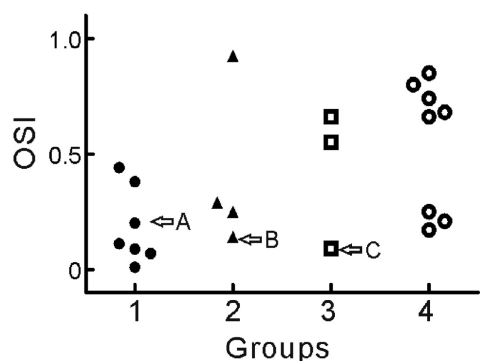

Figure 8. Response heterogeneity in the mouse SC. $A$, Confocal image of a putative narrow field vertical cell, whose soma was located $\sim 100 \mu \mathrm{m}$ below the SC surface (dashed line). A, Anterior; $D$, dorsal. $\boldsymbol{B}$, Confocal image of a putative wide field vertical cell, whose soma was $\sim 300 \mu \mathrm{m}$ below the SC surface (dashed line). Note that the dendritic arbors were probably truncated in these images because of sectioning. C, A horizontal cell with horizontally elongated dendrites (arrows). The SC surface is indicated by dashed lines. D, Scatter plots of receptive field sizes of different cell groups. The size was determined by counting the number of $5 \times 5^{\circ}$ grid points where flashing spots evoked responses. The example cells shown in $\boldsymbol{A}-\boldsymbol{C}$ are labeled with arrows. The group numbers correspond to those in supplemental Table 1 (available at www.jneurosci.org as supplemental material). Note that only three of the four group 2 cells responded. $\boldsymbol{E}, \boldsymbol{F}$, Distribution of DSI (E) and OSI $(\boldsymbol{F})$ of different groups. All values were obtained after cortical lesion.

width, and its axon extended parallel to the SC surface in deeper layers. This cell had a small receptive field, covering only nine grid locations (Fig. 8D) (see Materials and Methods). However, across the population, the smaller dendritic fields of these cells did not necessarily lead to smaller receptive fields. In fact, the distribution of their receptive field sizes covered a wide range, comparable with other groups (Fig. 8D). Similarly, wide ranges of direction and orientation selectivity were seen for these cells (Fig. $8 E, F$ ). The putative WFV neurons were located in the lower SGS and had wider dendritic trees (Fig. $8 B$ ), consistent with a previous report in rats (Langer and Lund, 1974). Although the cell in Figure $8 B$ had a huge receptive field, covering almost the entire stimulus monitor, the other cells in this group had smaller receptive fields similar to the putative NFV cells (Fig. $8 D$ ).

Horizontal cells (Fig. $8 C$ ) are believed to be prominent in providing long-range lateral inhibition in the SGS (Langer and Lund, 1974; Lee et al., 2001). However, the three identified horizontal cells all had compact and circular receptive fields (Fig. $8 D$ ), despite their horizontally extended dendritic fields. The other putative inhibitory neurons had similar sizes of receptive fields (Fig. $8 D$ ), but appeared to be more direction and orientation selective than other cell types (Fig. 8E,F). Together, these experiments reveal that the same subtypes of SGS neurons have wide ranges of response properties, including receptive field size and direction/orientation tuning. However, because of the limited number of cells in each subtype, we could not confirm or rule out whether different subtypes of SGS neurons have different tuning properties.

\section{Discussion}

\section{Receptive field properties in the mouse SC}

Although mice have been an instrumental model in the study of visual system development and plasticity, only a handful of pa- pers have reported visually evoked retinotopic maps or singleunit responses in its most prominent central visual structure, the SC (Dräger and Hubel, 1975; Mrsic-Flogel et al., 2005; Chandrasekaran et al., 2007; Cang et al., 2008). We have therefore provided the first quantitative and thorough analysis of response properties of superficial SC neurons in wild-type mice. First, we quantified the spatial structure of collicular receptive fields. The size of ON and OFF subfields we determined is in line with previous studies, although subfields were not separately analyzed previously (Dräger and Hubel, 1975; Chandrasekaran et al., 2007). By separating the ON and OFF subfields, we were able to quantify their spatial relationship and demonstrate that they widely overlap in most neurons. It is estimated that $70-80 \%$ of mouse RGCs are ON- or OFF-centered cells (Tian and Copenhagen, 2003; Liu et al., 2007), whose receptive fields are of similar size as those of the SC neurons (Balkema and Pinto, 1982; Stone and Pinto, 1993). Because each SC neuron is estimated to be innervated by approximately six RGCs (Chandrasekaran et al., 2007), the converging inputs must contain balanced ON- and OFF-centered cells with overlapping receptive fields. Consequently, developmental mechanisms must exist to map neighboring ON- and OFF-centered RGCs onto the same SC neurons. In support of this idea, it was observed that fewer SC neurons showed both ON and OFF responses in mutant mice that have altered spontaneous retinal activity during development (Chandrasekaran et al., 2007). In other words, correlated activity may be able to converge neighboring RGCs onto the same SC neurons.

We studied the tuning properties of individual SC neurons in response to drifting sinusoidal gratings. Only one study had previously investigated direction-selective responses in the mouse SC (Dräger and Hubel, 1975). Using moving spots, they found 11 of 46 cells (24\%) in the superficial layers to be direction selective, 
slightly less than the percentage we observed (30\%; with DSI > 0.5 ). Interestingly, they noted that most of these cells (8 of 11) and all of the selective ones in deeper layers preferred upward motion (Dräger and Hubel, 1975). We did not observe such a bias in preferred directions, possibly because of the difference in the used stimuli and/or the limited sampling in the early paper. Consistent with the mostly unbiased distribution that we observed, RGCs that prefer each of the four cardinal directions exist in the mouse retina (Elstrott et al., 2008) and project to the SC (Kim et al., 2008; Huberman et al., 2009). Whether and how these RGCs contribute to the direction selectivity of individual SC neurons remain to be revealed in future studies.

We found that a number of superficial SC neurons display orientation selectivity, a tuning property often associated with cortical neurons. We demonstrated that a similar level of orientation tuning persists in the SC in the absence of any cortical inputs. Therefore, orientation selectivity in the mouse SC must result from retinocollicular and/or intracollicular circuits. Because most SC neurons have overlapping ON and OFF receptive fields, the neuronal mechanisms underlying their orientation selectivity must be different from cortical simple cells, whose selectivity is thought to be determined by the spatial arrangement of $\mathrm{ON}$ - and OFF-centered geniculocortical inputs (Priebe and Ferster, 2008). It is therefore both important and informative to study the synaptic basis and developmental mechanisms of this and other tuning properties in the mouse SC. Our current data provide the necessary baseline information for future studies that will particularly benefit from genetic methods.

\section{Cortical influence and experience dependence}

In comparing collicular and cortical properties, we found that more cortical cells are selective for stimulus orientation and direction and show linear responses than collicular cells. A more relevant comparison is with layer 5 cells, since they are the ones projecting to the SC (Rhoades and Chalupa, 1978). Layer 5 cells are less selective and less linear (Niell and Stryker, 2008), more similar to SC neurons. This raised the possibility that cortical inputs may contribute to or modulate SC properties. Indeed, removing cortical inputs resulted in a decreased overlap between $\mathrm{ON}$ and OFF subfields, consistent with the vast majority of layer 5 cells being complex and presumably having overlapped $\mathrm{ON}$ and OFF receptive fields (Niell and Stryker, 2008). Another consequence of removing cortex was a change in preferred spatial frequency distribution. Although these changes clearly demonstrate that cortical inputs are functional in the SC, many collicular properties, such as orientation selectivity and linearity in our studies and size preference in the study by Chandrasekaran et al. (2007), do not change on cortical lesion. These results therefore provide essential foundation for future studies to dissect the specific contributions of retinocollicular and corticocollicular circuits to the function and development of the SC.

We find that long-term visual deprivation causes changes in response polarity and spatial frequency preference. These changes could result from deprivation-induced changes in the retina. However, this possibility is unlikely because dark rearing is known to increase the number ON-OFF-centered RGCs (Tian and Copenhagen, 2003; Liu et al., 2007), opposite to the effect seen in the SC. The effects of dark rearing on SC neurons could thus result from changes of cortical inputs and/or intracollicular connections. Remarkably, dark rearing did not alter orientation/ direction selectivity or subfield size in the SC. In V1, long-term visual deprivation is known to disrupt the normal development or maintenance of these properties (Chapman and Stryker, 1993;
Fagiolini et al., 1994). This difference may be attributable to different developmental time courses of the two structures. Studies in rats have shown that $\mathrm{SC}$ receptive fields around the time of eye opening had similar sizes (Binns and Salt, 1997a) and direction selectivity (Fortin et al., 1999) as in adults, whereas V1 receptive fields are still immature (Fagiolini et al., 1994). Consequently, there should be less experience-dependent refinement in the SC than V1. In hamster, even though there is a prolonged process when SC receptive fields become smaller after eye opening, this process does not require visual experience (Carrasco et al., 2005). Together, these studies and our data argue that visual experience plays a limited role in the development of SC receptive field properties.

\section{Comparative analyses of SC receptive field properties}

In contrast to the scarcity of functional studies in mice, the SC has been extensively studied in many other species. Like in mice, SC neurons in primates, cats, hamsters, and rats have mostly overlapped $\mathrm{ON}$ and $\mathrm{OFF}$ responses, although their receptive fields are smaller (Mcllwain and Buser, 1968; Cynader and Berman, 1972; Rhoades and Chalupa, 1977; Prévost et al., 2007). In all of these species, SC neurons decrease their responses when the stimulus increases beyond an optimum size (Mcllwain and Buser, 1968; Schiller and Stryker, 1972; Girman and Lund, 2007). The abundant GABAergic inhibitory interneurons in the superficial SC (Mize, 1992) may contribute to the size tuning. Importantly, these properties are consistent with the function of the SC, which has been well established as the visual structure necessary for orienting movements in hamsters (Schneider, 1969), cats (Harris, 1980), and monkeys (Schiller, 1972). Such orienting behaviors require head or eye movements toward spatially compact stimuli regardless of whether they are brighter or darker than the background. Another relevant property seen in the mouse SC is the selectivity for motion direction, which is also observed to varying degrees in cats $(\sim 64 \%)$ (McIlwain and Buser, 1968) and monkeys $(\sim 10 \%)$ (Cynader and Berman, 1972).

In contrast, the orientation-selective responses seen in mice are not observed in cat or monkey SC, but seen in the more closely related rats (Girman and Lund, 2007; Prévost et al., 2007). In addition, SC cells in mice are tuned to higher spatial frequencies $(\sim 0.08 \mathrm{cpd})$ (Fig. 4$)$ than neurons in their dLGN $(\sim 0.03$ cpd) (Grubb and Thompson, 2003) and V1 (Fig. 6) ( 0.02). This is different from what is seen in cats and rats where $\mathrm{V} 1$ neurons are tuned to higher spatial frequencies than SC (Movshon et al., 1978b; Pinter and Harris, 1981; Girman et al., 1999). The presence of orientation selectivity and preference for higher spatial frequency in the mouse SC suggest that the SC may not only be important for orienting behaviors but also, conceivably, play a larger role in mouse vision.

In conclusion, we find that the superficial SC neurons in mice have diverse and complex functional properties. With the simplicity of being just one synapse away from the retina and the ability to specifically alter gene function and activity, the mouse $\mathrm{SC}$ promises to be a powerful model system for vision research.

\section{References}

Andermann ML, Kerlin AM, Reid RC (2010) Chronic cellular imaging of mouse visual cortex during operant behavior and passive viewing. Front Cell Neurosci 4:3.

Balkema GW Jr, Pinto LH (1982) Electrophysiology of retinal ganglion cells in the mouse: a study of a normally pigmented mouse and a congenic hypopigmentation mutant, pearl. J Neurophysiol 48:968-980.

Bereshpolova Y, Stoelzel CR, Gusev AG, Bezdudnaya T, Swadlow HA (2006) 
The impact of a corticotectal impulse on the awake superior colliculus. J Neurosci 26:2250-2259.

Binns KE, Salt TE (1997a) Post eye-opening maturation of visual receptive field diameters in the superior colliculus of normal- and dark-reared rats. Brain Res Dev Brain Res 99:263-266.

Binns KE, Salt TE (1997b) Different roles for GABAA and GABAB receptors in visual processing in the rat superior colliculus. J Physiol 504:629-639.

Brainard DH (1997) The Psychophysics Toolbox. Spat Vis 10:433-436.

Callaway EM (2005) Structure and function of parallel pathways in the primate early visual system. J Physiol 566:13-19.

Cang J, Kaneko M, Yamada J, Woods G, Stryker MP, Feldheim DA (2005) Ephrin-as guide the formation of functional maps in the visual cortex. Neuron 48:577-589.

Cang J, Wang L, Stryker MP, Feldheim DA (2008) Roles of ephrin-as and structured activity in the development of functional maps in the superior colliculus. J Neurosci 28:11015-11023.

Carrasco MM, Razak KA, Pallas SL (2005) Visual experience is necessary for maintenance but not development of receptive fields in superior colliculus. J Neurophysiol 94:1962-1970.

Chandrasekaran AR, Shah RD, Crair MC (2007) Developmental homeostasis of mouse retinocollicular synapses. J Neurosci 27:1746-1755.

Chandrasekaran AR, Furuta Y, Crair MC (2009) Consequences of axon guidance defects on the development of retinotopic receptive fields in the mouse colliculus. J Physiol 587:953-963.

Chapman B, Stryker MP (1993) Development of orientation selectivity in ferret visual cortex and effects of deprivation. J Neurosci 13:5251-5262.

Clandinin TR, Feldheim DA (2009) Making a visual map: mechanisms and molecules. Curr Opin Neurobiol 19:174-180.

Cynader M, Berman N (1972) Receptive-field organization of monkey superior colliculus. J Neurophysiol 35:187-201.

Dräger UC, Hubel DH (1975) Responses to visual stimulation and relationship between visual, auditory, and somatosensory inputs in mouse superior colliculus. J Neurophysiol 38:690-713.

Dräger UC, Hubel DH (1976) Topography of visual and somatosensory projections to mouse superior colliculus. J Neurophysiol 39:91-101.

Elstrott J, Anishchenko A, Greschner M, Sher A, Litke AM, Chichilnisky EJ, Feller MB (2008) Direction selectivity in the retina is established independent of visual experience and cholinergic retinal waves. Neuron 58:499-506.

Fagiolini M, Pizzorusso T, Berardi N, Domenici L, Maffei L (1994) Functional postnatal development of the rat primary visual cortex and the role of visual experience: dark rearing and monocular deprivation. Vision Res 34:709-720.

Fagiolini M, Katagiri H, Miyamoto H, Mori H, Grant SG, Mishina M, Hensch TK (2003) Separable features of visual cortical plasticity revealed by $\mathrm{N}$-methyl-D-aspartate receptor 2A signaling. Proc Natl Acad Sci U S A 100:2854-2859.

Fortin S, Chabli A, Dumont I, Shumikhina S, Itaya SK, Molotchnikoff S (1999) Maturation of visual receptive field properties in the rat superior colliculus. Brain Res Dev Brain Res 112:55-64.

Girman SV, Lund RD (2007) Most superficial sublamina of rat superior colliculus: neuronal response properties and correlates with perceptual figure-ground segregation. J Neurophysiol 98:161-177.

Girman SV, Sauvé Y, Lund RD (1999) Receptive field properties of single neurons in rat primary visual cortex. J Neurophysiol 82:301-311.

Grubb MS, Thompson ID (2003) Quantitative characterization of visual response properties in the mouse dorsal lateral geniculate nucleus. J Neurophysiol 90:3594-3607.

Harris LR (1980) The superior colliculus and movements of the head and eyes in cats. J Physiol 300:367-391.

Hensch TK (2005) Critical period plasticity in local cortical circuits. Nat Rev Neurosci 6:877-888.

Hofbauer A, Dräger UC (1985) Depth segregation of retinal ganglion cells projecting to mouse superior colliculus. J Comp Neurol 234:465-474.

Huberman AD, Manu M, Koch SM, Susman MW, Lutz AB, Ullian EM, Baccus SA, Barres BA (2008) Architecture and activity-mediated refinement of axonal projections from a mosaic of genetically identified retinal ganglion cells. Neuron 59:425-438.

Huberman AD, Wei W, Elstrott J, Stafford BK, Feller MB, Barres BA (2009) Genetic identification of an On-Off direction-selective retinal ganglion cell subtype reveals a layer-specific subcortical map of posterior motion. Neuron 62:327-334.
Kim IJ, Zhang Y, Yamagata M, Meister M, Sanes JR (2008) Molecular identification of a retinal cell type that responds to upward motion. Nature 452:478-482.

Langer TP, Lund RD (1974) The upper layers of the superior colliculus of the rat: a Golgi study. J Comp Neurol 158:418-435.

Lee PH, Schmidt M, Hall WC (2001) Excitatory and inhibitory circuitry in the superficial gray layer of the superior colliculus. J Neurosci 21:8145-8153.

Liu BH, Li P, Li YT, Sun YJ, Yanagawa Y, Obata K, Zhang LI, Tao HW (2009) Visual receptive field structure of cortical inhibitory neurons revealed by two-photon imaging guided recording. J Neurosci 29:10520-10532.

Liu X, Grishanin RN, Tolwani RJ, Rentería RC, Xu B, Reichardt LF, Copenhagen DR (2007) Brain-derived neurotrophic factor and TrkB modulate visual experience-dependent refinement of neuronal pathways in retina. J Neurosci 27:7256-7267.

Luo L, Callaway EM, Svoboda K (2008) Genetic dissection of neural circuits. Neuron 57:634-660.

McIlwain JT, Buser P (1968) Receptive fields of single cells in the cat's superior colliculus. Exp Brain Res 5:314-325.

McLaughlin T, O’Leary DD (2005) Molecular gradients and development of retinotopic maps. Annu Rev Neurosci 28:327-355.

Mize RR (1992) The organization of GABAergic neurons in the mammalian superior colliculus. Prog Brain Res 90:219-248.

Movshon JA, Thompson ID, Tolhurst DJ (1978a) Receptive field organization of complex cells in the cat's striate cortex. J Physiol 283:79-99.

Movshon JA, Thompson ID, Tolhurst DJ (1978b) Spatial and temporal contrast sensitivity of neurones in areas 17 and 18 of the cat's visual cortex. J Physiol 283:101-120.

Mrsic-Flogel TD, Hofer SB, Creutzfeldt C, Cloëz-Tayarani I, Changeux JP, Bonhoeffer T, Hübener M (2005) Altered map of visual space in the superior colliculus of mice lacking early retinal waves. J Neurosci 25:6921-6928.

Niell CM, Stryker MP (2008) Highly selective receptive fields in mouse visual cortex. J Neurosci 28:7520-7536.

Niell CM, Stryker MP (2010) Modulation of visual responses by behavioral state in mouse visual cortex. Neuron 65:472-479.

Pelli DG (1997) The VideoToolbox software for visual psychophysics: transforming numbers into movies. Spat Vis 10:437-442.

Pinault D (1996) A novel single-cell staining procedure performed in vivo under electrophysiological control: morpho-functional features of juxtacellularly labeled thalamic cells and other central neurons with biocytin or Neurobiotin. J Neurosci Methods 65:113-136.

Pinter RB, Harris LR (1981) Temporal and spatial response characteristics of the cat superior colliculus. Brain Res 207:73-94.

Prévost F, Lepore F, Guillemot JP (2007) Spatio-temporal receptive field properties of cells in the rat superior colliculus. Brain Res 1142:80-91.

Priebe NJ, Ferster D (2008) Inhibition, spike threshold, and stimulus selectivity in primary visual cortex. Neuron 57:482-497.

Priebe NJ, Mechler F, Carandini M, Ferster D (2004) The contribution of spike threshold to the dichotomy of cortical simple and complex cells. Nat Neurosci 7:1113-1122.

Prusky GT, Douglas RM (2004) Characterization of mouse cortical spatial vision. Vision Res 44:3411-3418.

Prusky GT, Alam NM, Beekman S, Douglas RM (2004) Rapid quantification of adult and developing mouse spatial vision using a virtual optomotor system. Invest Ophthalmol Vis Sci 45:4611-4616.

Razak KA, Pallas SL (2006) Dark rearing reveals the mechanism underlying stimulus size tuning of superior colliculus neurons. Vis Neurosci 23:741-748.

Rhoades RW, Chalupa LM (1977) Differential effects of stimulus size on "on" and "off" responses of superior collicular neurons. Exp Neurol 57:57-66.

Rhoades RW, Chalupa LM (1978) Functional properties of the corticotectal projection in the golden hamster. J Comp Neurol 180:617-634.

Schiller PH (1972) The role of the monkey superior colliculus in eye movement and vision. Invest Ophthalmol 11:451-460.

Schiller PH, Stryker M (1972) Single-unit recording and stimulation in superior colliculus of the alert rhesus monkey. J Neurophysiol 35:915-924.

Schiller PH, Finlay BL, Volman SF (1976) Quantitative studies of single-cell properties in monkey striate cortex. I. Spatiotemporal organization of receptive fields. J Neurophysiol 39:1288-1319. 
Schneider GE (1969) Two visual systems. Science 163:895-902.

Skottun BC, De Valois RL, Grosof DH, Movshon JA, Albrecht DG, Bonds AB (1991) Classifying simple and complex cells on the basis of response modulation. Vision Res 31:1079-1086.

Stone C, Pinto LH (1993) Response properties of ganglion cells in the isolated mouse retina. Vis Neurosci 10:31-39.

Tian N, Copenhagen DR (2003) Visual stimulation is required for refinement of $\mathrm{ON}$ and $\mathrm{OFF}$ pathways in postnatal retina. Neuron 39:85-96.

Tokunaga A, Otani K (1976) Dendritic patterns of neurons in the rat superior colliculus. Exp Neurol 52:189-205.

Triplett JW, Owens MT, Yamada J, Lemke G, Cang J, Stryker MP, Feldheim DA (2009) Retinal input instructs alignment of visual topographic maps. Cell 139:175-185.
Umino Y, Solessio E, Barlow RB (2008) Speed, spatial, and temporal tuning of rod and cone vision in mouse. J Neurosci 28:189-198.

Wang BS, Sarnaik R, Cang J (2010) Critical period plasticity matches binocular orientation preference in the visual cortex. Neuron 65:246256.

Wang L, Rangarajan KV, Lawhn-Heath CA, Sarnaik R, Wang BS, Liu X, Cang J (2009) Direction-specific disruption of subcortical visual behavior and receptive fields in mice lacking the $\beta 2$ subunit of nicotinic acetylcholine receptor. J Neurosci 29:12909-12918.

Wilson CJ, Sachdev RN (2004) Intracellular and juxtacellular staining with biocytin. Curr Protoc Neurosci 1:1.12.

Zhang F, Aravanis AM, Adamantidis A, de Lecea L, Deisseroth K (2007) Circuit-breakers: optical technologies for probing neural signals and systems. Nat Rev Neurosci 8:577-581. 